\title{
The effect of vanadyl treatment on vascular responsiveness of streptozotocin-diabetic rats
}

\author{
A. T. Özçelikay ${ }^{1}$, C. Pekiner ${ }^{1}$, N. Ari ${ }^{1}$, Y. Öztürk ${ }^{2}$, A. Özüari ${ }^{1}$, V.M.Altan ${ }^{1}$ \\ ${ }^{1}$ Department of Pharmacology, Faculty of Pharmacy, University of Ankara, Ankara, Turkey \\ ${ }^{2}$ Department of Pharmacology, Faculty of Pharmacy, University of Anadolu, Eskisehir, Turkey
}

Summary Vanadyl sulphate has been demonstrated to possess insulin-like effects in streptozotocin (STZ) diabetic rats, including the normalization of hyperglycaemia and the prevention of diabetes-induced cardiac dysfunction. However, the effectiveness of vanadyl sulphate on diabetes-related vascular aberrations has not been questioned. Hence, in the present work, we have specifically addressed the question of whether chronic oral vanadyl sulphate treatment has any beneficial effect on diabetes-induced changes in vascular reactivity. Male albino rats were injected with a single intravenous dose of STZ $(55 \mathrm{mg} / \mathrm{kg})$. Vanadyl sulphate was administered in the drinking water at a concentration of $1 \mathrm{mg} / \mathrm{ml}$ from 7 days after the STZ injection and treatment was maintained for 10 weeks. Vanadyl intake was accompanied by decreased blood glucose and serum insulin levels. The effects of diabetes on vascular smooth muscle function were assessed by the responsiveness of aortae to noradrenaline and $\mathrm{KCl}$. Contractile responses of the diabetic aortae were found to be significantly increased as compared with controls. However, there were no significant differences in $\mathrm{pD}_{2}$ values of the agonists in either of the groups. Treatment of diabetic rats with vanadylsulphate completely prevented the increases in responsiveness of aortae to noradrenaline and $\mathrm{KCl}$. The effect of diabetes on the fast and slow components of noradrenaline-induced contraction was also examined. Both components of the response to noradrenaline were significantly increased in diabetic aortae. These changes were also prevented by vanadyl sulphate treatment. The data demonstrate that 10 -week vanadyl sulphate treatment results in improved vascular reactivity of diabetic rats. [Diabetologia (1994) 37:572-578]

Key words Streptozotocin, diabetic rat, aorta, contraction, vanadyl treatment.
The cardiovascular diseases that result from diabetes mellitus which are responsible for most of the diabetic morbidity and mortality have been described in various clinical and experimental settings $[1,2]$. Several studies have indicated that a greater incidence of vascular disease is found in patients with insulin-dependent or noninsulin-dependent diabetes than in the general popula-

Received: 19 October 1993

and in revised form: 24 February 1994

Corresponding author: Dr. V.M. Altan, University of Ankara, Faculty of Pharmacy, Department of Pharmacology, 06100 Tandogan, Ankara Turkey

Abbrevations: STZ, streptozotocin; VST, vanadyl sulphate trihydrate. tion $[3,4]$. Although the aetiology of vascular disorders in diabetes is not understood, it has been suggested that alterations in the sensitvity and/or responsiveness of vascular smooth muscle to neurotransmitters and circulating hormones may underlie the functional abnormalities of blood vessels in diabetes $[5,6]$. In this regard, the responsiveness of isolated vascular preparations from STZ or alloxan-diabetic rats has been studied extensively [7-13]. Although the results of these studies are somewhat inconclusive, the discrepancies might be attributed to differences in experimental conditions such as techniques for measuring contractile force, expression of contractile force, gender, and severity and duration of diabetes. Nevertheless, in many of these studies, it was demonstrated that arteries from STZ-diabetic rats were more responsive to the contractile effects of noradrenaline $[7,8,14-16]$. The increased 


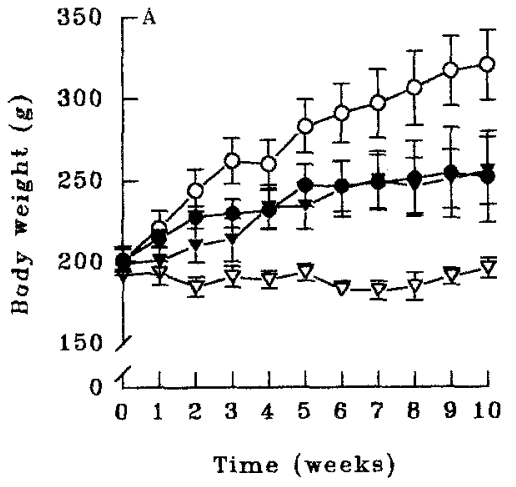

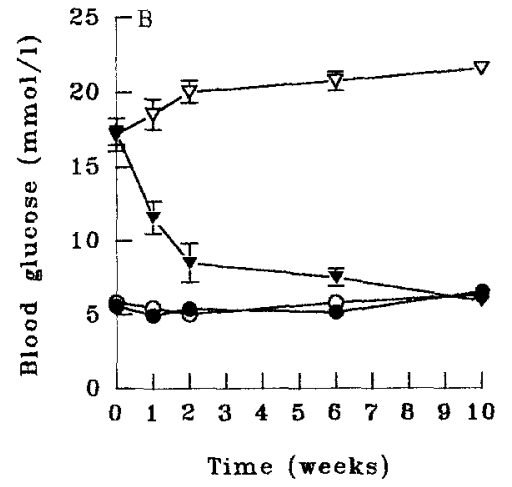

Fig.1A,B. Effect of administration of vanadyl on body weight (A) and blood glucose (B) levels of untreated control $(n=20, O)$, vanadyl treated control $(n=5, \bullet)$, untreated diabetic $(n=17, \nabla)$ and vanadyl treated diabetic rats $(n=11, \boldsymbol{\nabla})$. Values are means $\pm \mathrm{SEM}$ responsiveness of vascular smooth muscle to noradrenaline was also demonstrated to be prevented from occurring, or reversed once established, by treatment of diabetic rats with insulin [8].

Vanadium compounds have been shown to possess several insulin-mimetic actions both in vivo and in vitro. These include enhancement of glucose transport and oxidation in rat adipocytes $[17,18]$ and skeletal muscle $[19,20]$, stimulation of pentose phosphate pathway [21] and glycogen synthase activity in rat adipocytes [22], enhancement of glycogen synthesis in the liver and diaphragm [23], inhibition of lipolysis [24] and activation of lipogenesis in rat adipocytes [25] and reduction of insulin requirement in spontaneously diabetic (BB Wistar) rats [26]. It has also been shown that vanadium compounds, both in the vanadate and vanadyl forms, lower plasma glucose and prevent the decline in cardiac performance [26-30] due to diabetes when administered to intact experimentally-induced diabetic rats. To our knowledge, however, no data are available on the effect of vanadium treatment on vascular aberrations in diabetes. Hence, in the present study, the contractile effects of noradrenaline and $\mathrm{KCl}$ on aortic rings obtained from control and diabetic rats were compared, and the effect of chronic oral VST treatment on vascular reactivity was investigated.

\section{Materials and methods}

Induction of experimental diabetes. Male albino rats, weighing $150-200 \mathrm{~g}$, were used in the present investigation. The rats were lightly anaesthetized with ether, and either STZ $(55 \mathrm{mg} / \mathrm{kg})$ in citrate buffer ( $\mathrm{pH} 4.5$ ) or citrate buffer alone was administered by injection into the lateral tail vein. After 3 days, blood glucose levels were determined using an Ames glucometer (Miles Laboratories Inc., Elkhart, Ind., USA), and rats with blood glucose levels of $14 \mathrm{mmol} / \mathrm{l}$ or above were considered to be diabetic.

Vanadyl treatment. The control and diabetic rats were randomly divided from 7 days after the STZ injection into two subgroups: one group was given plain tap water (untreated control and untreated diabetic), and the other group was given drinking water containing VST ( $1 \mathrm{mg} / \mathrm{ml}$; treated control and treated diabetic). The rats were maintained for 10 weeks with free access to food and water. The rats were weighed once per week and average fluid intake was recorded daily. The average vanadyl intake by each animal in the treated groups, on the other hand, was calculated by multiplying average fluid intake by the vanadyl concentration used. Blood glucose levels were also monitored at the end of weeks 1,2 and 6. Final plasma glucose levels were measured on samples taken when the rats were killed.

Isolation of aortic rings. Rats were killed by stunning followed by decapitation. The thoracic aorta was excised from each animal and placed in Krebs-Ringer bicarbonate buffer solution with the following composition (mmol/l): $\mathrm{NaCl}(118), \mathrm{KCl}(4.7), \mathrm{CaCl}_{2}$ (2.5), $\mathrm{MgSO}_{4} .7 \mathrm{H}_{2} \mathrm{O}(1.2), \mathrm{KH}_{2} \mathrm{PO}_{4}(1.2), \mathrm{NaHCO}_{3}(25)$ and glucose (11.1). The aorta was cleaned of adhering fat and connective tissue and cut into rings $5 \mathrm{~mm}$ long. In all experiments, the luminal surface of the preparation was rubbed to remove endothelium. The removal of the endothelium was confirmed by the inability of arteries precontracted with noradrenaline $\left(10^{-5}\right.$ $\mathrm{mol} / \mathrm{l})$ to relax in response to acteylcholine $\left(5.10^{-6} \mathrm{mmol} / \mathrm{l}\right)$. Aortic rings were suspended in isolated tissue baths filled with $20 \mathrm{ml}$ of Krebs solution continuously bubbled with a mixture of $5 \% \mathrm{CO}_{2} 95 \% \mathrm{O}_{2}(\mathrm{pH} 7.4)$ at $37^{\circ} \mathrm{C}$. One end of the aortic ring was connected to a tissue holder and the other to an isometric force transducer (Ugo Basile, No. 7004, Varese, Italy) connected to a microdynamometer (Ugo Basile, Unirecord). The rings were equilibrated for $90 \mathrm{~min}$ under a resting tension of $2 \mathrm{~g}$. During the equilibration period the solution in the tissue bath was replaced every $30 \mathrm{~min}$. At the end of this period, dose-response curves were obtained with noradrenaline and $\mathrm{KCl}$. Noradrenaline $\left(10^{-8}-10^{-5} \mathrm{~mol} / \mathrm{l}\right)$ and $\mathrm{KCl}(10-50 \mathrm{mmol} / \mathrm{l})$ were added in a cumulative manner until a maximal response was achieved. After the addition of each dose, a plateau response was obtained before the addition of a subsequent dose. At the end of each experiment, tissue was blotted dry, measured and weighed, and its cross-sectional area was calculated using the following formula:

Cross-sectional area $\left(\mathrm{mm}^{2}\right)=$

weight $(\mathrm{mg}) \cdot$ length $(\mathrm{mm})^{-1} \cdot \operatorname{density}\left(\mathrm{mg} / \mathrm{mm}^{3}\right)^{-1}$

The density of the preparations was assumed to be $1.05 \mathrm{mg} / \mathrm{mm}^{3}$ [31]. Before starting the dose-response curves with noradrenaline and $\mathrm{KCl}$, the aortic rings were exposed to $10^{-5} \mathrm{~mol} / 1 \mathrm{nor}$ adrenaline until the contraction reached the plateau (approximately $10 \mathrm{~min}$ ) in order to measure the fast and slow components of vascular response to noradrenaline. The fast component of the response was measured from the baseline to the point at which the rate of contraction started to decrease abruptly; the slow component, on the other hand, was measured from this point to the top of the contraction [32]. The total response was the sum of these two components.

Determination of blood glucose and serum insulin. Glucose was determined from a drop of whole blood from a cut from the rat 
Table 1. Some characteristics of vanadyl treated or untreated diabetic and control rats

\begin{tabular}{lcccccc}
\hline & Body weight $(\mathrm{g})$ & $\begin{array}{l}\text { Fluid intake } \\
(\mathrm{ml} / \mathrm{day})\end{array}$ & $\begin{array}{l}\text { Vanadyl intake } \\
\left(\mathrm{mg} \cdot \mathrm{kg}^{-1} \cdot \mathrm{day}^{-1}\right)\end{array}$ & $\begin{array}{l}\text { Blood glucose } \\
(\mathrm{mmol} / \mathrm{l})\end{array}$ & $\begin{array}{l}\text { Serum insulin } \\
(\mathrm{mU} / \mathrm{l})\end{array}$ & $\begin{array}{l}\text { Cross sectio- } \\
\text { nal area }\left(\mathrm{mm}^{2}\right)\end{array}$ \\
\hline Control rats & & & & & & \\
Untreated & $320.0 \pm 21.4$ & $37.5 \pm 0.9^{\mathrm{b}}$ & - & $6.3 \pm 0.29$ & $26.13 \pm 2.22^{\mathrm{a}}$ & $1.16 \pm 0.02$ \\
Vanadyl treated & $252.0 \pm 28.0$ & $22.6 \pm 0.7$ & $73.5 \pm 2.8$ & $6.5 \pm 0.56$ & $17.67 \pm 1.14$ & $1.14 \pm 0.04$ \\
Diabetic rats & & & & & & \\
Untreated & $195.6 \pm 6.20^{\mathrm{d}}$ & $156.1 \pm 3.1^{\mathrm{a}}$ & - & $21.5 \pm 0.50^{\mathrm{a}}$ & $12.06 \pm 1.29$ & $0.80 \pm 0.04^{\mathrm{a}}$ \\
Vanadyl treated & $255.8 \pm 20.5$ & $28.5 \pm 1.4^{\mathrm{c}}$ & $95.5 \pm 5.2^{\mathrm{c}}$ & $5.9 \pm 0.13$ & $18.48 \pm 2.26$ & $1.12 \pm 0.05$ \\
\hline
\end{tabular}

${ }^{a}$ Significantly different from all other groups $(p<0.05)$

${ }^{\mathrm{b}}$ Significantly different from vanadyl treated control and diabetic groups $(p<0.05)$
${ }^{\mathrm{S}}$ Significantly different from vanadyl treated control group $(p<0.05)$

d Significantly different from untreated control group $(p<0.05)$ Values are mean \pm SEM of 5-20 observations in each group

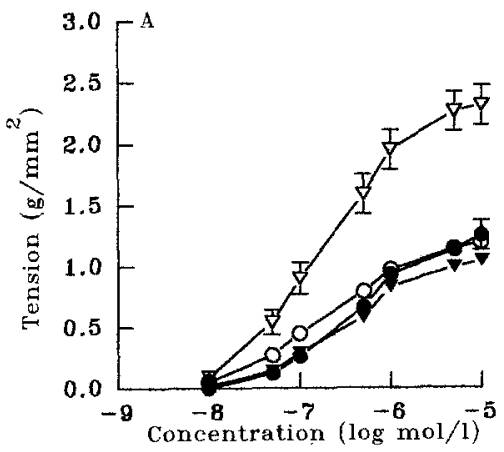

tail and measured with an Ames Glucometer and glucose-sensitive sticks. Blood was collected at the time of death and centrifuged at $(2,000 \mathrm{~g}$ for $5 \mathrm{~min})$. Resulting serum samples were analysed for insulin levels by standard radioimmunoassay techniques using a commercial kit available from DPC (Diagnostic Products Corporation, Los Angeles, Calif., USA).

The drugs used came from the following sources: STZ and noradrenaline (Sigma, St Louis, Mo., USA), VST (Aldrich, Milwaukee, Wis., USA) and $\mathrm{KCl}$ (Baker, Phillipsburg, N.J., USA).

Data analysis. Contractile responses to noradrenaline and $\mathrm{KCl}$ were calculated as the increase in tension $(g)$ in response to the agonist per cross-sectional area of aorta $\left(\mathrm{mm}^{2}\right)$. Agonist $\mathrm{pD}_{2}$ value (apparent agonist affinity constants; $-\log \mathrm{ED}_{50}$ ) were calculated from each agonist dose-response curve by linear regression analysis of the linear portion of the curve and taken as a measure of the sensitivity of the tissues to each agonist. All values are expressed as means \pm SEM. Statistical differences were evaluated using one-way analysis of variance (ANOVA) followed by Neuman-Keul's test. Results were considered to be significantly different at $p$ less than 0.05 .

\section{Results}

The body weights of rats in each experimental group are shown in Figure 1 and Table 1. The body weights of untreated diabetic rats were significantly less than those of untreated controls. The rate of growth in all groups was decreased relative to the untreated control group. However, treatment with VST caused a slight increase in the growth of diabetic rats although body weights of diabetic rats were still lower than those of control rats after treatment. Fluid and VST intake by the rats are shown in Table 1. Fluid intake, as expected, was markedly increased in diabetic rats given only drinking water as compared with untreated control rats. During treatment with VST, fluid intake was lowered in both control and diabetic rats below the level of untreated controls. VST intake (expressed as average self-administered dose per rat), on the other hand, was higher in diabetic than in control rats.

Blood glucose levels of control and diabetic rats at the end of the 10 weeks in the absence or presence of VST are demonstrated in Table 1. As expected, blood glucose levels were elevated in the untreated-diabetic rats. The blood glucose concentrations of control rats treated with VST were unchanged while elevated blood glucose concentrations of diabetic rats were completely normalized after VST treatment. As shown in Figure 1, blood glucose levels of diabetic rats reached near to untreated control levels within 6 weeks of VST treatment, and during the remaining period of study they were similar in the two groups. The induction of STZ-diabetes, on the other hand, also resulted in reduced serum insulin levels (Table 1). Interestingly, a significant decrease in the insulin levels was also observed in control rats after VST treatment. The serum insulin levels of diabetic rats treated with VST remained decreased as well.

The influence of VST treatment on the reactivity of thoracic aortae from rats with STZ-induced diabetes was also investigated in this study. The cross-sectional 
Table 2. $\mathrm{pD}_{2}$ values for noradrenaline and $\mathrm{KCl}$ in aortae from vanadyl treated or untreated control and diabetic rats

\begin{tabular}{lll}
\hline Groups & Noradrenaline & $\mathrm{KCl}$ \\
\hline Control rats & & \\
Untreated & $6.69 \pm 0.05$ & $1.74 \pm 0.01$ \\
Vanadyl treated & $6.45 \pm 0.06$ & $1.78 \pm 0.01$ \\
Diabetic rats & & \\
Untreated & $6.68 \pm 0.05$ & $1.77 \pm 0.01$ \\
Vanadyl treated & $6.53 \pm 0.08$ & $1.76 \pm 0.01$ \\
\hline
\end{tabular}

Values are mean \pm SEM of 5-20 observations in each group

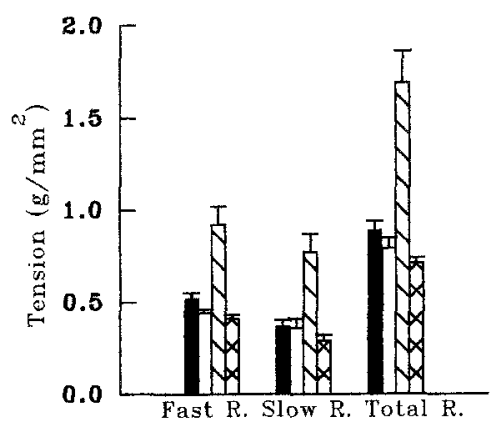

Fig.3. Fast, slow and total responses of noradrenaline $(10$ ${ }^{5} \mathrm{~mol} / \mathrm{l}$ ) in aortas from untreated control ( $n=20$, solid bars), vanadyl treated control ( $n=5$, open bars), untreated diabetic ( $n=17$, hatched bars) and vanadyl treated diabetic rats $(n=11$, diagonal crosshatch). Values are means \pm SEM

areas of aortae from untreated diabetic rats were significantly less than those of untreated controls (Table 1). However, as also shown in Table 1, treatment of diabetic rats with VST prevented this decrease. VST treatment also prevented the change in the reactivity of diabetic aortae to both noradrenaline and $\mathrm{KCl}$ (Fig.2). Contractile responses of aortae to noradrenaline $\left(10^{-8}-10^{-5} \mathrm{~mol} / \mathrm{l} /\right.$ are shown in Figure 2. Concentrations of noradrenaline greater than $10^{-8} \mathrm{~mol} / \mathrm{l}$ produced much greater increases in tension in aortae from untreated-diabetic rats than in aortae from untreated control rats. Aortae from untreated diabetic rats also responded to $\mathrm{KCl}(10-50 \mathrm{mmol} / \mathrm{l} /$ with much greater increases in tension than those from untreated control rats (Fig. 2). In contrast, response of aortae from VST-treated diabetic rats to both noradrenaline and $\mathrm{KCl}$ were very similar to those of aortae from controls (Fig. 2). However, no change in $\mathrm{pD}_{2}$ values for noradrenaline and $\mathrm{KCl}$ from either untreated or VST-treated diabetic rats compared with controls was detected (Table 2). Since it has been well established that vascular response to noradrenaline can be divided from the mechanical point of view into fast and slow components, in the present work, the effects of STZ diabetes and of VST treatment on the mechanical response to $10^{-5} \mathrm{~mol} / \mathrm{l}$ noradrenaline were also characterized. As shown in Figure 3, either fast or slow components of total response to noradrenaline were found to be significantly greater in untreated-diabetic rats than untreated controls. VST treatment, on the other hand, normalized the increased fast and slow components of noradrenaline response in diabetic aortae.

\section{Discussion}

It is evident from the present study that treatment with oral VST restored the altered vascular reactivity to agonists in 10-week diabetic rats. The abilities of vanadium compounds to stimulate the insulin receptor kinase [33-35] as well as to prolong receptor activation [36] and also to exert post-receptor effects [37,38] have all been proposed as possible mechanisms of action. Recognition of similarities between the physiological properties of vanadium and insulin raised the possibility that vanadium compounds may have a role in regulating both glucose metabolism and cardiac performance. Among the many recognized physiologic changes associated with STZ-induced diabetes are a depression in working heart performance [27-29, 39], and an alteration in vascular reactivity to various vasoactive agents $[7-9,13,14]$. The defects in isolated heart functions of diabetic rats have been demonstrated to be reversible following chronic daily insulin injections [39] and oral vanadium therapy [27].

The present investigation confirms previous reports that oral VST treatment normalizes the increased blood glucose levels of STZ-diabetic rats [26, 28, 29]. As expected, blood glucose levels were elevated in diabetic rats but returned to normal following chronic (10-weeks) VST treatment. Blood glucose levels of control rats, however, were not affected by VST treatment. On the other hand, body weights of diabetic animals treated with VST were improved to a certain extent but they were still lower than those of untreated controls.

The results of the present study also demonstrate that aortae from 10-week STZ-diabetic rats are more responsive to the contractile effects of either noradrenaline or $\mathrm{KCl}$ than are aortae from corresponding controls, while VST treatment prevented these changes in responsiveness. The increased vascular responsiveness of STZ-diabetic rats observed in our study is in agreement with previous reports $[8,14,40]$ on noradrenaline contraction, and [7], for $\mathrm{KCl}$ contraction. Among the mechanisms that could have been involved in the alterations of vascular smooth muscle function in diabetic rats are enhanced phosphoinositide metabolism [41], increased adrenergic stimulation [10, 15], enhanced sensitivity of calcium channels $[10,14,40]$ and deficient endothelial activity $[42,43]$. Since all experiments in the present investigation were carried out in aortae in which the endothelium had been mechanically removed, the underlying mechanism does not appear to be due to a decrease in the release of endotheliumderived relaxing factors. It is also unlikely that a change in either the density or the affinity of the alpha-adreno- 
ceptors took place in diabetic aortae, since the increases in tension of diabetic aortae in response to noradrenaline obtained in the present investigation occurred in the absence of any significant changes in sensitivity ( $\mathrm{pD}_{2}$ value) to the catecholamine. Rather, it seems more likely that there is an alteration in the coupling of alpha receptors to the mobilization of $\mathrm{Ca}^{2+}$. Recently, Abebe et al. [14] have reported that enhanced contractile responses of aortae from rats with chronic STZ-diabetes to alpha-adrenoceptor agonists are largely dependent on the presence of extracellular $\mathrm{Ca}^{2+}$. The enhanced responsiveness to $\mathrm{KCl}$ observed in aortae from STZ-diabetic rats in the present study, also indicates an increased $\mathrm{Ca}^{2+}$ entry.

As is well known, the contraction of the rat aorta to noradrenaline occurs in two phases: a rapid initial contraction (fast response) is followed by a slow further increase in tension (slow response) [44-46]. The slow response is dependent on the influx of extracellular $\mathrm{Ca}^{2+}$ whereas $\mathrm{Ca}^{2+}$ from intracellular sources is utilized for the fast response [44, 45]. Recently, Rinaldi and Cingolani [32] have shown that the fast component of noradrenaline-induced contraction was increased while the slow component was depressed in spontaneously diabetic rats. The total response to noradrenaline in Rinaldi and Cingolani's study, however, was found to be not significantly different in diabetic rats compared with controls. Contrary to the observation of these investigators [32], we found an enhanced total response to noradrenaline in which the fast and slow components were both significantly increased in 10-week STZ-diabetic rat aortas. Both phases of the response to noradrenaline, however, were normalized with VST treatment of diabetic rats. The differences between our results and those of Rinaldi and Cingolani [32] could be at least partly due to the species of diabetic rats and/or the duration of diabetes.

It is apparent from the results of the present study that treatment of diabetic rats with VST prevented the increased responsiveness of aortae to noradrenaline and $\mathrm{KCl}$, and also prevented the enhanced fast and slow components of noradrenaline response. The mechanism(s) responsible for the promoting effect of VST on vascular reactivity of STZ-diabetic rats in the present study remain unclear. Some possible explanations, however, might be deduced from the results obtained in the present study and from those obtained in previous studies demonstrating the glucose lowering effect of vanadium treatment of diabetic animals occurred in the absence of increases in the endogenous levels of insulin $[28,29]$. In addition, in the present study, circulating insulin levels of non-diabetic control animals were demonstrated to be decreased with vanadium treatment while euglycaemia was being maintained as demonstrated in several other studies [27,30]. These findings led to the suggestion that vanadium is able to substitute for insulin under in vivo conditions. On the other hand, vanadyl treatment has recently been shown to potentiate the in vivo glucose lowering effect of insulin in STZ-diabetic rats and to produce a decline in the dosage of insulin required for the maintenance of a non-glycosuric state in spontaneously diabetic $\mathrm{BB}$ rats [26]. Moreover, treatment of diabetic rats with insulin has been demonstrated to prevent or reverse the increased responsinvess of aortae to noradrenaline [8]. The above-mentioned ability of insulin could be the result of a chronic effect of insulin treatment, either directly on vascular smooth muscle or indirectly via its action on glucose metabolism [8]. In a recent study by Mongold et al. [47], it was demonstrated that muscle vanadium levels of diabetic rats treated with vanadyl sulphate (up to $1 \mathrm{mg} / \mathrm{ml}$ in drinking water) were well below the in vitro active concentrations. It is, therefore, unlikely that VST at the concentration used in our experiments might have a direct effect on glucose metabolism in muscle, but might increase the sensitivity of vascular smooth muscle to the effects of insulin. These findings alternatively raise the possibility that vanadyl may be able to enhance the responsiveness of tissues to low circulating levels of insulin [28, 48-51]. Thus, it might be speculated that the effectiveness of endogenous insulin on vascular activity is then re-established in the STZ-diabetic rats treated with vanadyl although the present study has no direct evidence to support this possibility.

In conclusion, the present findings demonstrate that 10 -week VST treatment can be beneficial in restoring the changes in vascular reactivity of STZ-diabetic rats. The effectiveness of VST occurs by its insulin-like actions. However, its mechanism(s) of action on vascular reactivity remain unclear and require further investigation.

Acknowledgements. This work was supported by a grant from Ankara University Research Foundation.

\section{References}

1. Kannel WB, McGee DL (1979) Diabetes and cardiovascular risk factors. The Framingham Study. Circulation 59: 8-131

2. Nagano M, Dhalla NS (1991) The diabetic heart. In: Rodrigues B, McNeill JH (eds) Functional evaluation of hearts upon treating diabetic animals with various interventions. Raven Press, Ltd., New York, pp 21-34

3. Garcia MJ, McNamara PM, Gordon T, Kannell WB (1974) Morbidity and mortality in diabetics in the Framingham population sixteen-year follow-up study. Diabetes 23: 104 111

4. Colwell JA, Halushka PV, Sarji KE, Lopes-Virella MF, Sagel J (1979) Vascular disease in diabetes: pathophysiological mechanisms and therapy. Arch Intern Med 139:225-230

5. Christlieb AR, Janka HV, Solano A (1976) Vascular reactivity to angiotensin II and to norepinephrine in diabetic subjects. Diabetes 25: 268-274

6. Weidmann P, Beretta-Picoli C, Keusch G, et al (1979) Sodium-volume factor, cardiovascular reactivity and hypertensive mechanism of diuretic therapy in mild hypertension associated with diabetes mellitus. Am J Med 657: 779-784 
7. MacLeod KM, McNeill JH (1985) The influence of chronic experimental diabetes on contractile responses of rat isolated blood vessels. Can J Physiol Pharmacol 63: 52-57

8. MacLeod KM (1985) The effect of insulin treatment on changes in vascular reactivity in chronic, experimental diabetes. Diabetes 34: 1160-1167

9. White RD, Carrier GO (1988) Enhanced vascular alphaadrenergic neuroeffector system in diabetes: importance of calcium. Am J Physiol 255: H1036-H1042

10. Owen MP, Carrier GO (1980) Calcium dependence of norepineprine-induced vascular contraction in experimental diabetes. J Pharmacol Exp Ther 212: 253-258

11. Ramanadham S, Tenner TE (1984) Alterations in aortic and tail artery reactivity to agonists after STZ treatment. Can J Physiol Pharmacol 62: 418-423

12. Agrawal DK, Bhimji S, McNeill JH (1987) Effects of chronic experimental diabetes on vascular smooth muscle function in rabbit carotid artery. J Cardiovasc Pharmacol 9: 584-593

13. Pfaffman MA, Ball CR, Darby A, Hilman R (1982) Insulin reversal of diabetes-induced inhibition of vascular contractility in the rat. Am J Physiol 242: H490-H495

14. Abebe W, Harris KH, MacLeod KM (1990) Enhanced contractile responses of arteries from diabetic rats to alpha-1 adrenoceptor stimulation in the absence and presence of extracellular $\mathrm{Ca}^{2+}$. J Cardiovasc Pharmacol 16: 239-248

15. Harris KH, MacLeod KM (1988) Influence of the endothelium on contractile responses of arteries from diabetic rats. Eur J Pharmacol 153: 55-64

16. Kamata K, Miyata N, Kasuya Y (1988) Mechanisms of increased responses of the aorta to alpha-adrenoceptor agonists in streptozotocin-diabetic rats. J Pharmacobio Dyn 11: 707-713

17. Shechter Y, Karlish SJD (1980) Insulin-like stimulation of glucose oxidation in rat adipocytes by vanadyl (IV) ions. Nature (Lond) 284: 556-558

18. Dubyak GR, Kleinzeller AD (1980) The insulin-mimetic effects of vanadate in isolated rat adipocytes. J Biol Chem 255: $5306-5312$

19. Clausen T, Andersen TL, Stürup-Johansen M, Petkova O (1981) The relationship between the transport of glucose and cations across cell membranes in isolated tissues. The effect of vanadate on ${ }^{45} \mathrm{Ca}$-efflux and sugar transport in adipose tissue and in skeletal muscle. Biochim Biophys Acta 646: 261-267

20. Clark AS, Fagan FM, Mitch WE (1985) Selectivity of the insulin-like actions of vanadate on glucose and protein metabolism in skeletal muscle. Biochem J 232: 273-276

21. Duckworth WC, Solomon SS, Liepnicks J, Hamel FG, Hand S, Peavy DE (1988) Insulin-like effects of vanadate in isolated rat adipocytes. Endocrinology 122: 2285--2289

22. Tamura S, Brown TA, Whipple JH, et al. (1984) A novel mechanism for the insulin-like effect of vanadate on glycogen synthase in rat adipocytes. J Biol Chem 259: 66506658

23. Tolman EL, Barris E, Burns M, Pansini A, Partridge R (1979) Effects of vanadium on glucose metabolism in vitro. Life Sci 25: 1159-1164

24. Degani H, Gochin M, Karlish SJD, Shechter Y (1981) Electron paramagnetic resonance studies and insulin-like effects of vanadium in rat adipocytes. Biochemistry 20: 5795-5799

25. Schecter Y, Ron A (1986) Effect of depletion of phosphate and bicarbonate ions on insulin action in rat adipocytes. $J$ Biol Chem 261: 14945-14950

26. Ramanadham S, Cros GH, Mongold JJ, Serrano JJ, McNeill JH (1990) Enhanced in vivo sensitivity of vanadyltreated diabetic rats to insulin. Can J Physiol Pharmacol 68: 486-491
27. Heyliger CE, Tahiliani AG, McNeill JH (1985) Effect of vanadate on elevated blood glucose and depressed cardiac performance on diabetic rats. Science 227: 1474-1477

28. Ramanadham S, Mongold JJ, Brownsey RW, Cros GH, McNeill JH (1989) Oral vanadyl sulfate in treatment of diabetes mellitus in rats. Am J Physiology 257: H904--H911

29. Ramanadham S, Brownsey RW, Cros GH, Mongold JJ, McNeill JH (1989) Sustained prevention of myocardial and metabolic abnormalities in diabetic rats following withdrawal from oral vanadyl treatment. Metabolism 38: 10221028

30. Özçelikay AT, Yildizoglu-Ari N, Özüari A, Öztürk Y, Altan VM (1993) The effect of vanadate on alloxan-diabetic rat atria. Diabetes Res Clin Prac 19: 189-194

31. Wyse DG (1980) On 'the normalization' of active developed force of isolated helical strips of muscular and elastic arteries for variation in wall thickness. J Pharm Methods 4: $313-326$

32. Rinaldi GJ, Cingolani HE (1992) Effect of diabetes on fast response to norepinephrine in rat aorta. Diabetes $41: 30-34$

33. Tamura S, Brown TA, Dubler RE, Larner J (1984) Insulinlike effect of vanadate on adipocyte glycogen synthase and on phosphorylation of 95.000 dalton subunit of insulin receptor. Biochem Biophys Res Commun 113: 80-86

34. Bernier M, Laird DM, Lane MD (1988) Effect of vanadate on the cellular accumulation of pp 15. an apparent product of insulin receptor tyrosine kinase action. J Biol Chem 263: 13525-13534

35. Cordera R, Andraghetti G, DeFronzo RA, Rosetti L (1990) Effect of vivo vanadate treatment on insulin receptor tyrosine kinase activity in partially pancreatectomized diabetic animals. Endocrinology 126: 2177-2183

36. Fantus EG, Kadota S, Deragon G, Foster B, Posner B (1989) Pervanadate [peroxide(s) of vanadate] mimics insulin action in rat adipocytes via activation of the insulin receptor tyrosine kinase. Biochemistry 28: 8864-8871

37. Green A (1986) The insulin-like effect of sodium vanadate on adipocyte glucose transport is mediated at a post insulin receptor level. Biochem J 238: 663-669

38. Strout HV, Vicario PP, Saperstein S, Slater FE (1989) The insulin-mimetic effect of vanadate is not correlated with insulin receptor tyrosine kinase activity or phosphorylation in mouse diaphragm in vivo. Endocrinology 124: 19181924

39. Paulson DJ, Kopp SJ, Tow JP, Peace DG (1987) Effects of vanadate on in vivo myocardial reactivity to norepinephrine in diabetic rats. J Pharmacol Exp Ther 240: 529-534

40. Scarbrough NL, Carrier GO (1984) Nifedipine and alpha adrenoceptors in rat aorta $\mathrm{I}$. Role of extracellular calcium in enhanced alpha-2 adrenoceptor-mediated contraction in diabetes. J Pharmacol Exp Ther 231: 603-609

41. Abebe W, MacLeod KM (1991) Enhanced arterial contractility to noradrenaline in diabetic rats is associated with increased phosphoinositide metabolism. Can J Physiol Pharmacol 69: 355-361

42. Karasu Ç, Altan VM (1993) The role of endothelial cells on the alterations in vascular reactivity induced by insulin-dependent diabetes mellitus: effects of insulin treatment. Gen Pharmacol 24: 743-755

43. Altan VM, Karasu C, Özüari A (1989) The effects of type-1 and type-2 diabetes on endothelium-dependent relaxation in rat aorta. Pharmacol Biochem Behav 33: 519-522

44. Godfraind T, Kaba A (1972) The role of calicum in the action of drugs on vascular smooth muscle. Archs Int Pharmacodyn Ther [Suppl] 196: 35-49

45. Downing OA, Wilson KA, Wilson VG (1983) Non-compotative antagonism of the alpha-adrenoceptor-mediated fast 
component of contraction of the rat aorta, by doxazosin and prazosin. Br J Pharmac 80: 315-322

46. Bohr DF (1963) Vascular smooth muscle: dual effect of calcium. Science 139: 597-599

47. Mongold JJ, Cros GH, Vian L et al. (1990) Toxicological aspects of vanadyl sulphate on diabetic rats: effects of vanadium levels and pancreatic B-cell morphology. Pharmacol Toxicol 67: 192-198

48. Challiss RAJ, Leighton B, Lozeman FJ, Budohoski L, Newsholme EA (1987) Effects of chronic administration of vanadate to the rat on the sensitivity of glycolysis and glycogen synthesis in skeletal muscle to insulin. Biochem Pharmacol 36: $357-361$
49. Blondel O, Bailbe D, Portha B (1989) In vivo insulin resistance in streptozotocin-diabetic rats-evidence for reversal following oral vanadate treatment. Diabetologia 32: 185190

50. Brichard SM, Lederer J, Henquin JC (1991) The insulin-like properties of vanadium: a curiosity or a perspective for the treatment of diabetes? Diabete Metab 17: 435-440

51. Eriksson JW, Lönnroth P, Smith U (1992) Vanadate increases cell surface insulin binding and improves insulin sensitivity in both normal and insulin-resistant rat adipocytes. Diabetologia 35 : 510-516 